\title{
Sensorless control of Fault Tolerant PMSM drives in case of single-phase open circuit fault
}

\author{
Kamel Saleh \\ Electrical Engineering Dept \\ An-Najah National University \\ Nablus, West Bank \\ Kamel.saleh@najah.edu
}

\author{
Mark Sumner \\ School of electrical engineering \\ Nottingham University \\ Nottingham,UK \\ Mark.sumner@nottingham.ac.uk
}

\begin{abstract}
This paper introduces a new method to track the saliency of a PMSM motor fed by a four-leg inverter in case of a single phase open circuit fault through measuring the dynamic current response of the motor line currents due the IGBT switching actions. In the case of a single phase open circuit fault, a fault-tolerant control strategy that includes taking appropriate actions to control the two remaining healthy currents, resulting in minor system performance degradation. The new strategy introduced in this paper includes software modifications only to the saliency tracking algorithm used in healthy mode to make it applicable to the reconfigured converter in the presence of a fault. The new method uses only the fundamental PWM waveform (i.e there is no modification to the operation of the four-leg inverter) similar to the fundamental PWM method proposed for a three-leg inverter. Simulation results are provided to verify effectiveness of the proposed strategy of saliency tracking of a PMSM motor driven by fault tolerant four-phase inverter over a wide speed ranges under the case of a single phase open circuit fault.
\end{abstract}

Keywords-Sensorless; four leg inverter; single phase open circuit; SVPWM.

\section{INTRODUCTION (HEADING 1)}

Tracking the saliency of ac motors fed by two level three-leg inverters has been widely researched for healthy mode systems. At low and zero speed, some form of additional excitation has been proposed, such as the injection of a high frequency (HF) voltage or current [1-3] or the injection of test pulses [4-6].

In some applications such that in the coiling and spooling textile machines and that of the aerospace and automotive (electric cars) industry, the safety procedures extremely demands a continued operation of the motor drive system after a fault has occurred to reduce the impact of the fault on the system operation. And hence, number of fault tolerant strategies for sensored ac motor drives have been used to enhance the system operation under open phase faults. The fault tolerant strategies proposed [7 ] are based on the connection of either the stator winding neutral point or the motor phase to the dc link middle point of the two level three -leg inverter through a triac .[8] proposed a two level four-leg inverter where the fourth leg is connected to the neutral point of the motor in the case of open circuit phase fault. In [9] the fourth leg is connected to the neutral point in healthy and faulty cases and so 3D space vector modulation is introduced. [10] proposed the switch function algorithm for a four-leg converter to synthesize redefined output waveforms under fault conditions. However, the approaches to track the saliency in the fault-tolerant inverters have received little attention in the literature.

This paper proposes a fault tolerant, four-phase inverter PMSM drive topology which can be used to track the saturation saliency in PM motors and rotor slotting saliency in induction motors in the case of single phase open circuit faults in order to maintain a continues system operation with a satisfactory performance to meet the safety procedure for the whole system and increase the reliability of the system.

\section{FAULT TOLERANT TWO LEVEL FOUR-LEG CONVERTER DRIVE TOPOLOGY}

Fig 1 shows the proposed fault tolerant two level four-leg converter drive topology [11]. In this topology, a fourth-leg is added to the conventional three-leg inverter and the redundant leg is permanently connected the motor neutral point to provide the fault tolerant capability in case of an open phase fault. Under healthy operating conditions, the fourth-leg will be redundant which means that the two switches in this leg will be inactivated resulting in no connection between the supply and the motor neutral point. Therefore, the proposed converter normally operates as a conventional two level three-leg inverter. Under faulted operating conditions, the switches on the faulty phase are disabled and the switches in the fourth phase are immediately activated in order to control the voltage at the neutral point of motor.

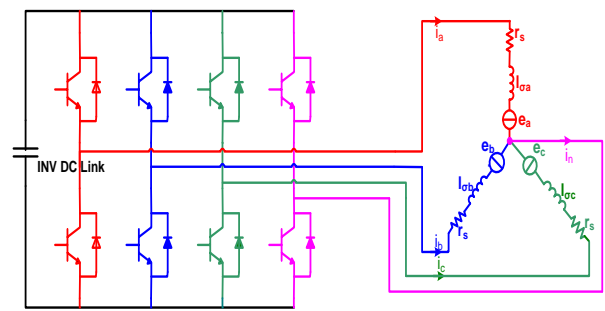

Fig1 The fault tolerant two level four-leg converter motor drive configuration. 


\section{SENOSRED CONTROL STRATEGY FOR THE FAULT TOLERANT MOTOR DRIVE}

Indirect vector control is employed to control the speed of the motor speed in both normal and faulted operating conditions.

\section{A. Normal operating condition in sensored mode}

Figure 2 shows the vector control structure used for the two level four-leg inverter motor drive under normal operation in sensored mode. The three phase motor currents are transformed to the d-q synchronous rotating frame, id and iq, as given in (1) to compare to the reference values. The reference voltages (vd and $\mathrm{Vq}$ ) generated from the controller are transformed back using eq 2 to a three phase quantities which then delivered to the space vector modulator to generate the appropriate switching signals for the fault tolerant inverter switches.

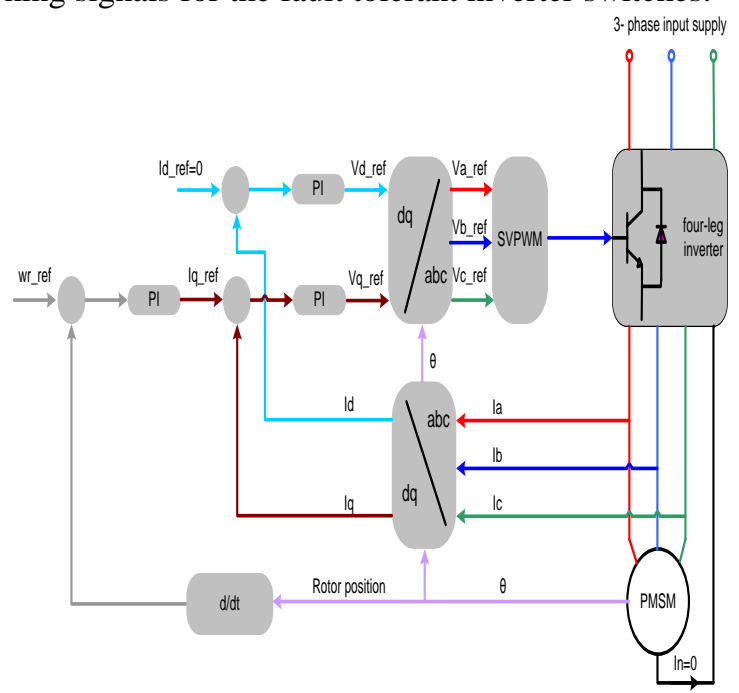

Fig 2 Control structure of four-leg PMSM drive under healthy operating condition

$$
\begin{gathered}
{\left[\begin{array}{l}
\mathrm{Iq} \\
\mathrm{Id} \\
\mathrm{I} 0
\end{array}\right]=\frac{2}{3}\left[\begin{array}{ccc}
\cos (\theta) & \cos (\theta-120) & \cos (\theta+120) \\
\sin (\theta) & \sin (\theta-120) & \sin (\theta+120) \\
0.5 & 0.5 & 0.5
\end{array}\right]\left[\begin{array}{l}
\mathrm{Ia} \\
\mathrm{Ib} \\
\mathrm{Ic}
\end{array}\right](1)} \\
{\left[\begin{array}{l}
V a \\
V b \\
V c
\end{array}\right]=\left[\begin{array}{ccc}
\cos (\theta) & \sin (\theta) & 1 \\
\cos (\theta-120) & \sin (\theta-120) & 1 \\
\cos (\theta+120) & \sin (\theta+120) & 1
\end{array}\right]\left[\begin{array}{l}
V q \\
V d \\
V 0
\end{array}\right]}
\end{gathered}
$$

where $\theta$ is the rotor angle of the reference frame. I0 is the zero sequence current while In is the motor neutral current as expressed in (1) and (2), respectively. Under normal operation the neutral current is always zero.

\section{B. Open phase fault operation}

The modification introduced to the control strategy of the system under open phase fault condition is illustrated in Figure 3 [12]. Firstly, In order to disable the switches in the faulty phase, the reference voltage of the faulty phase is set to zero. In this structure, it is assumed that phase ' $b$ ' is opened so the motor current in phase ' $b$ ' drops to zero and Vb_ref is set to zero whereas the motor neutral current, which is the sum of the two remaining output currents(Ia and Ic), can circulate through the fourth phase of the inverter. Secondly, by adopting $\mathrm{Ib}=0$ in (1), it can be seen that in order to keep the motor performance under faulty operation, the rotating MMF obtained from the armature currents $(\mathrm{Ia}, \mathrm{Ib}, \mathrm{Ib})$ in healthy condition, should be maintained by the two remaining motor currents $(\mathrm{Ia}, \mathrm{Ic})$ in the case of open circuit fault that demands an increasing by $\sqrt{3}$ as well as phase shifting 30 degrees away from the faulted phase compared to the currents generated under normal operation as given in equation

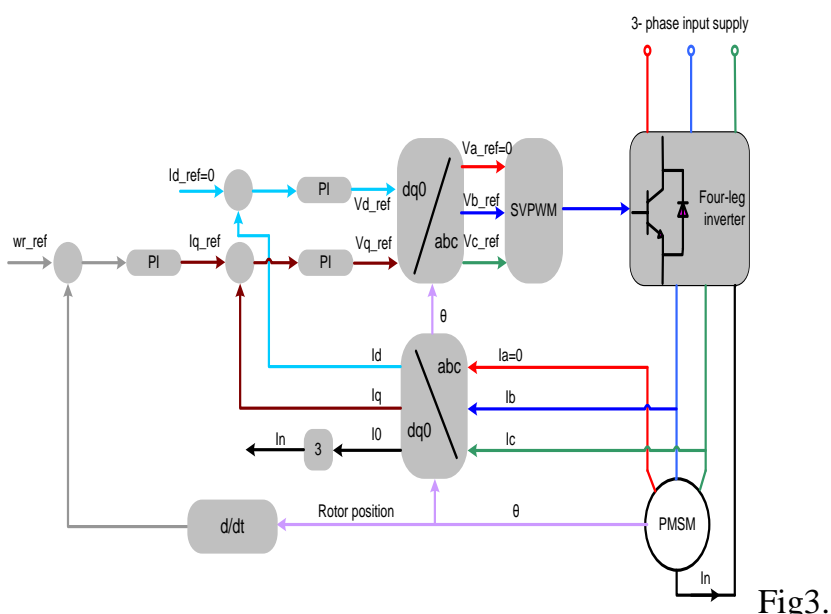

The vector control structure for the four-phase inverter PMSM drive under a phase ' $b$ ' open-circuit fault.

$$
\left[\begin{array}{l}
I a \\
I 0 \\
I c
\end{array}\right]=\left[\begin{array}{cc}
\sqrt{3} \cos (\theta+30) & \sqrt{3} \sin (\theta-30) \\
-\cos (\theta-120) & -\sin (\theta-120) \\
\sqrt{3} \operatorname{co}(\theta+90) & \sqrt{3} \sin (\theta+90)
\end{array}\right]\left[\begin{array}{l}
V q \\
V d
\end{array}\right]
$$

\section{Simulation Results}

The simulation of four-leg converter PMSM drive has been carried out using SABER. A $5 \mathrm{Nm}$ load torque and a $500 \mathrm{rpm}$ speed command are applied to the system. Figure 4 shows the simulation results of the four-leg converter PMSM drive system under healthy and faulted conditions. It is clear that the controller could regulate the motor speed to follow the reference speed properly under normal operating condition. The controlled currents id and iq are stable at the reference levels while the motor currents are balanced three-phase sinusoidal. The phase ' $b$ ' open circuit fault is introduced at the time of $2.5 \mathrm{~s}$. As the switches in the fourth leg of the inverter are not activated yet then $\mathrm{In}=0$, and $\mathrm{I} 0=0$, and as the sum of three current equals to zero then Ia and Ic currents increase in magnitude with phase shifting 180 degrees with respect to each other. It can be seen in this period significant ripple in Id and Iq in this period which leads to significant ripple in torque and speed. At 3.0s, the switch of the fourth leg are activated which means that the neutral is connected to the supply. The simulation results show that ripple in the torque is significantly reduced and almost the 
same as under normal operating condition. The currents id and iq are now controlled Properly

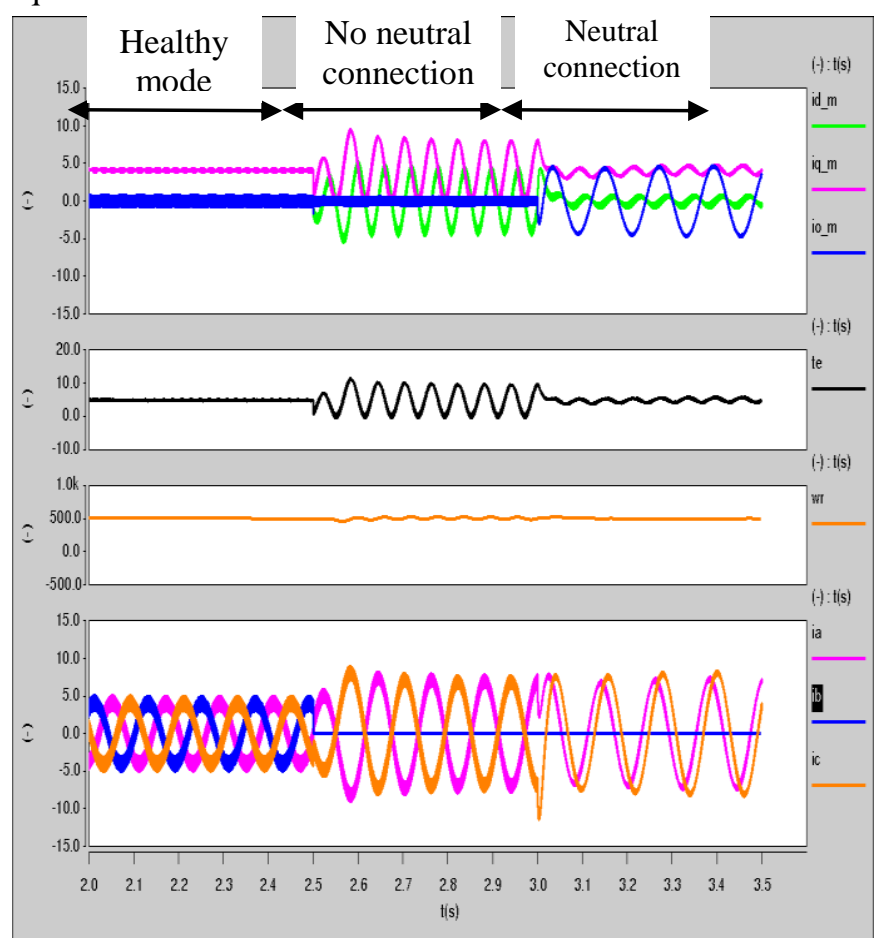

Fig 4 Performance of a four-phase PMSM drive system under different operating conditions.

\section{TRACKING THE SATURATION SALIENCY OF PMSM UNDER HEALTHY CONDITION}

The stator leakage inductances of the induction motor are modulated by anisotropy either from the rotor slotting or from the saturation of the main flux. The modulation can be expressed by the following equations :-

$$
\begin{aligned}
& l \sigma a=L_{0}+\Delta L \cos \left(n_{a n} \theta_{a n}\right) \\
& l \sigma b=L_{0}+\Delta L \cos \left(n_{a n}\left(\theta_{a n}-\frac{2 \pi}{3}\right)\right. \\
& l \sigma c=L_{0}+\Delta L \cos \left(n_{a n}\left(\theta_{a n}-\frac{4 \pi}{3}\right)\right.
\end{aligned}
$$

Where $L_{0}$ is the average inductance and $\Delta L$ is the variation of leakage inductance due to the rotor anisotropy ( $n_{a n}=2$ for saturation anisotropy )

This modulation of the stator leakage inductances will be reflected in the transient response of the motor line current to the test vector imposed by the inverter. So by using the fundamental PWM wave form and by measuring the transient current response to the active vectors it is possible to detect the inductance variation and track the rotor position as shown in [6] for three-leg inverter. Figure and table below illustrates this method

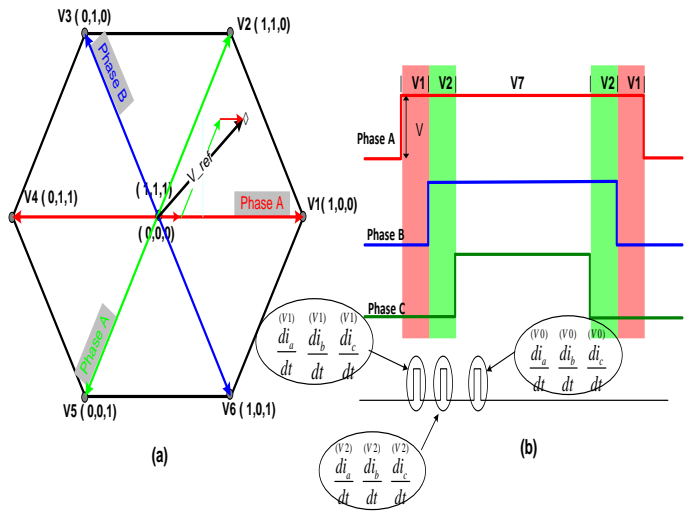

Fig5 SVPWM modulation technique of 3-leg inverter in healthy mode

Table 1 Selection of $\mathrm{pa}, \mathrm{pb}$ and $\mathrm{pc}$ in six sectors for a starconnected machine using fundamental PWM method

After obtaing the scalar quantities $\mathrm{pa}, \mathrm{pb}$ and $\mathrm{pc}$ then the position of the saliency can be constructed as shown in the equation below:-

$$
\overrightarrow{\mathrm{p}}=\mathrm{p}_{\alpha}+j p_{\beta}=\mathrm{p}_{\mathrm{a}}+a p_{\mathrm{b}}+\mathrm{a}^{2} \mathrm{p}_{\mathrm{c}}
$$

For four leg-inverter, under the healthy operation, the switches in the fourth leg will not be activated under healthy mode so the algorithm proposed in[6] to track the saliency for three-leg inverter PMSM drive system can be applied for the four-leg

\begin{tabular}{|c|c|c|c|}
\hline & $\mathrm{P}_{\mathrm{a}}$ & $P_{b}$ & $P_{c}$ \\
\hline $\mathrm{V} 1+\mathrm{V} 0$ & $2-c\left(\frac{\stackrel{d}{d i} i_{a}}{d t}-\frac{(V 0)}{d t}\right)$ & $-1-c\left(\frac{\stackrel{(V 1)}{d i_{c}}}{d t}-\frac{\stackrel{(V 0)}{d i_{c}}}{d t}\right)$ & $-1-c\left(\frac{\stackrel{(V 1)}{d i_{b}}}{d t}-\frac{(V 0)}{d i_{b}}\right)$ \\
\hline $\mathrm{V} 2+\mathrm{V} 0$ & $-1+c\left(\frac{\stackrel{(V 2)}{d i_{b}}}{d t}-\frac{(V 0)}{d i_{b}}\right)$ & $-1+c\left(\frac{\stackrel{(V 2)}{d i_{a}}}{d t}-\frac{(V 0)}{d i_{a}}\right)$ & $2+c\left(\frac{d i_{c}}{d t}-\frac{d i_{c}}{d t}\right)$ \\
\hline $\mathrm{V} 3+\mathrm{V} 0$ & $-1-c\left(\frac{\left(d_{c}\right)}{d t}-\frac{(V 0)}{d t}\right)$ & $2-c\left(\frac{d i_{b}}{d t}-\frac{d i_{b}}{d t}\right)$ & $-1-c\left(\frac{\stackrel{(V 3)}{d i_{a}}}{d t}-\frac{\stackrel{(V 0)}{d i_{a}}}{d t}\right)$ \\
\hline $\mathrm{V} 4+\mathrm{V} 0$ & $2+c\left(\frac{d i_{a}}{d t}-\frac{\stackrel{(V 0)}{d i_{a}}}{d t}\right)$ & $-1+c\left(\frac{d i_{c}}{d t}-\frac{\stackrel{(V 0)}{d i_{c}}}{d t}\right)$ & $-1+c\left(\frac{\stackrel{(V 4)}{d i_{b}}}{d t}-\frac{(V 0)}{d t}\right)$ \\
\hline $\mathrm{V} 5+\mathrm{V} 0$ & $-1-c\left(\frac{\left(V i_{b}\right.}{d t}-\frac{(V 0)}{d i_{b}}\right)$ & $-1-c\left(\frac{d i_{a}}{d t}-\frac{d i_{a}}{d t}\right)$ & $2-c\left(\frac{d i_{c}}{d t}-\frac{d i_{c}}{d t}\right)$ \\
\hline $\mathrm{V} 6+\mathrm{V} 0$ & $-1+c\left(\frac{d i_{c}}{d t}-\frac{(V 0)}{d t}\right)$ & $2+c\left(\frac{d i_{b}}{d t}-\frac{d i_{b}}{d t}\right)$ & $-1+c\left(\frac{(V 6)}{d t}-\frac{(V 0)}{d t}\right)$ \\
\hline
\end{tabular}
inverter PMSM drive system as shown if Fig 6. In open phase fault case, the measurement of the current response $(\mathrm{di} / \mathrm{dt})$ associated with the faulty phase will become zero i.e 
$\frac{\mathrm{di}}{\mathrm{dt}}^{\mathrm{V} 1}, \frac{\mathrm{di}}{\mathrm{bt}}^{\mathrm{V} 2}$ and $\frac{\mathrm{di}}{\mathrm{dt}}^{\mathrm{V} 0}$ become zeros as $\mathrm{ib}=0$. Table 1 shows that $\mathrm{Pa}$ is obtained using $\frac{d i_{b}}{d t}$ in sector 2 and $5, \mathrm{~Pb}$ is obtained using $\frac{d i_{b}}{d t}$ in sectors 3 and 6 and Pc is obtained using $\frac{d i_{b}}{d t}$ in sectors 1 and 4, which means that these position scalars will be zero in these sectors as seen in fig 6. More over the active vectors $\mathrm{V} 1, \mathrm{~V} 2$, and $\mathrm{V} 0$ in each sector won't be obtained by applying specific switching actions in phase $a, b$ and $c$ as in healthy case as there won't be any switching action in phase $b$ due to the fault. Hence the tracking saliency algorithm will be incorrect as shown if in Fig 6.

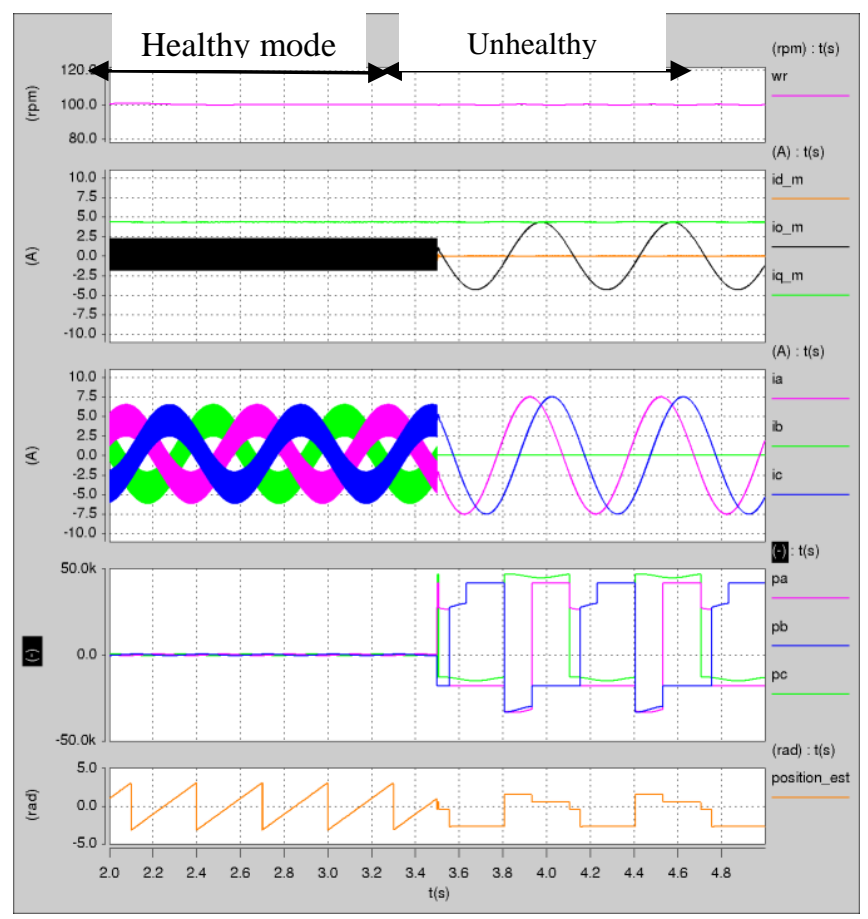

Fig 6 tracking the saliency saturation in healthy mode and phase a open circuit case using

\section{TRACKING THE SATURATION SALIENCY OF PMSM UNDER UNHEALTHY CONDITION}

Fig 6 shows that the algorithm presented in [6] to track the saliency can't be used under the case of phase open circuit case. In this section a modified algorithm will be applied to track the saliency in the case of open circuit fault case using the current response of application of fundamental PWM waveform (no modification applied to the PWM waveform).

Fig 7 shows the space vector modulation state diagram for 4leg inverter in case of open circuit phase fault case. If $\mathrm{V} \_$ref exists in first sector, then the switching sequences and the timing of the applied vectors will be :-

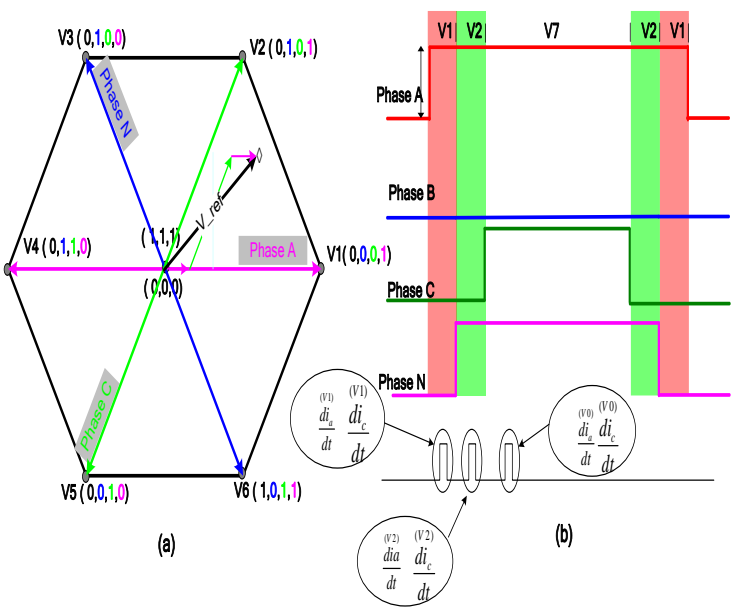

Fig7 SVPWM modulation technique in phase b open circuit fault case

The stator circuit when the vectors V1, V2 and V0 are applied are shown in Fig 8.a, 8.b and 8.c respectively.
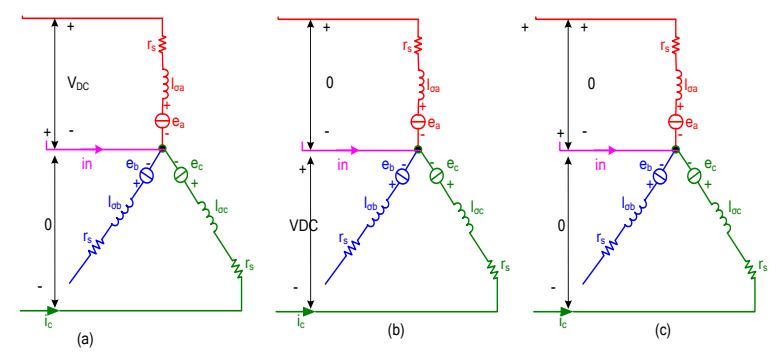

Fig 8 Stator circuits when: (a) V1 is applied; (b) V2 is applied;

(c) V0 is applied under phase b open circuit fault

Using the circuit in Fig 8.a, the following equations hold true:-

$\mathrm{V}_{\mathrm{DC}}=r_{s} * i_{a}^{(V 1)}+l_{\sigma a} * \frac{d i_{a}^{(V 1)}}{d t}+e_{a}^{(V 1)}$

$0=r_{s} * i_{c}^{(V 1)}+l_{\sigma c} * \frac{d i_{c}^{(V 1)}}{d t}+e_{c}^{(V 1)}$

The following equations are obtained using Fig 8.b:-

$0=r_{s} * i_{a}^{(V 2)}+l_{\sigma a} * \frac{d i_{a}^{(V 2)}}{d t}+e_{a}^{(V 2)}$

$-\mathrm{V}_{\mathrm{DC}}=r_{s} * i_{c}^{(V 2)}+l_{\sigma c} * \frac{d i_{c}^{(V 2)}}{d t}+e_{c}^{(V 2)}$

Finally when V0 is applied as shown in Fig 8.c, the following equations hold true:-

$0=r_{s} * i_{a}^{(V 0)}+l_{\sigma a} * \frac{d i_{a}^{(V 0)}}{d t}+e_{a}^{(V 0)}$
$0=r_{s} * i_{c}^{(V 0)}+l_{\sigma c} * \frac{d i_{c}^{(V 0)}}{d t}+e_{c}^{(V 0)}$

Assuming that the voltage drop across the stator resistances are small and can be neglected and the back emf can be cancelled if the time separation between the vectors is small.

Subtracting $(10,13)$ from $(11,9)$ respectively yields:- 


$$
\begin{gathered}
\mathrm{V}_{\mathrm{DC}}=l_{\sigma a} *\left(\frac{d i_{a}^{(V 1)}}{d t}-\frac{d i_{b}^{(V 0)}}{d t}\right) \\
\mathrm{V}_{\mathrm{DC}}=l_{\sigma c} *\left(\frac{d i_{c}^{(V 0)}}{d t}-\frac{d i_{c}^{(V 2)}}{d t}\right)
\end{gathered}
$$

\section{Finally}

$$
\begin{aligned}
& P a=\left(\frac{d i_{a}^{(V 1)}}{d t}-\frac{d i_{b}^{(V 0)}}{d t}\right) \\
& P c=\left(\frac{d i_{c}^{(V 0)}}{d t}-\frac{d i_{c}^{(V 2)}}{d t}\right)
\end{aligned}
$$

$\mathrm{Pb}$ can't be obtained from measuring the current response in phase $b$ as it is zero in the case of open circuit phase. But it can be deduced from $\mathrm{pa}$ and $\mathrm{pc}$ according to the following equation:-

$\mathrm{pb}=-\mathrm{pa}-\mathrm{pc} \quad(18)$

By doing the same procedures for other sectors, the following

\begin{tabular}{|c|c|c|c|}
\hline & $\mathrm{Pa}_{\mathrm{a}}$ & $\mathrm{Pb}$ & $\mathrm{P}_{\mathrm{c}}$ \\
\hline $\mathrm{V} 1+\mathrm{V} 2+\mathrm{V} 0$ & $\left(\frac{d i_{a}}{d t}-\frac{d i_{a}}{d t}\right)$ & $-\mathrm{P}_{\mathrm{a}}-\mathrm{P}_{\mathrm{c}}$ & $\left(\frac{d i_{c}}{d t}-\frac{d i_{c}}{d t}\right)$ \\
\hline $\mathrm{V} 2+\mathrm{V} 3+\mathrm{V} 0$ & $\left(\frac{d i_{a}}{d t}-\frac{d i_{a}}{d t}\right)$ & $-\mathrm{P}_{\mathrm{a}-} \mathrm{P}_{\mathrm{c}}$ & $\left(\frac{d i_{c}}{d t}-\frac{d i_{c}}{d t}\right)$ \\
\hline $\mathrm{V} 3+\mathrm{V} 4+\mathrm{V} 0$ & $\left(\frac{(V 0)}{d i_{a}} d t-\frac{(V 4)}{d i_{a}}\right)$ & $-P_{a}-P_{c}$ & $\left(\frac{d i_{c}}{d t}-\frac{d i_{c}}{d t}\right)$ \\
\hline $\mathrm{V} 4+\mathrm{V} 5+\mathrm{V} 0$ & $\left(\frac{(V 0)}{d t}-\frac{(V 4)}{d t}\right)$ & $-P_{a}-P_{c}$ & $\left(\frac{d i_{c}}{d t}-\frac{d i_{c}}{d t}\right)$ \\
\hline $\mathrm{V} 5+\mathrm{V} 6+\mathrm{V} 0$ & $\left(\frac{(V 0)}{d i_{a}} d t-\frac{(V 5}{d i_{a}}\right)$ & $-P_{a}-P_{c}$ & $\left(\frac{d i_{c}}{d t}-\frac{d i_{c}}{d t}\right)$ \\
\hline $\mathrm{V} 6+\mathrm{V} 1+\mathrm{V} 0$ & $\left(\frac{d i_{a}}{d t}-\frac{(V 0)}{d i_{a}}\right)$ & $-P_{a}-P_{c}$ & $\left(\frac{d i_{c}}{d t}-\frac{d i_{c}}{d t}\right)$ \\
\hline
\end{tabular}
table can be construct:-

Table2 Selection of pa, $\mathrm{pb}$ and $\mathrm{pc}$ for a star-connected machine in phase b open circuit fault case.

Figure 8 shows the results of the simulation after modifying the tracking saliency algorithm as in Table 2. The figure shows that the new algorithm can track the saliency in the case of open circuit phase $b$ fault with the same quality as in healthy condition.

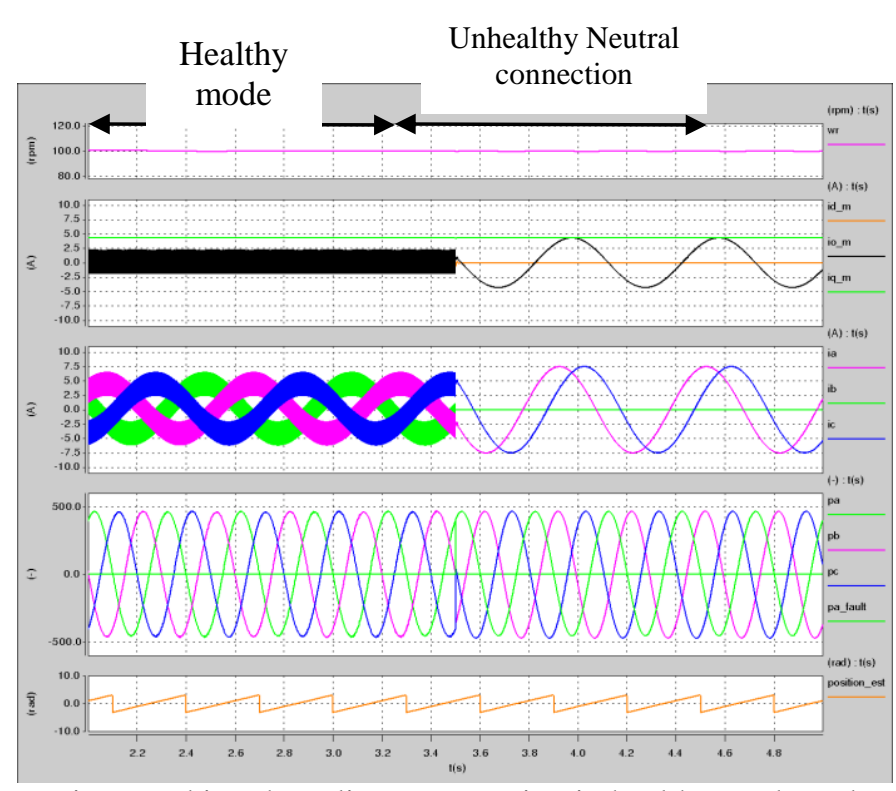

Fig 9 tracking the saliency saturation in healthy mode and phase a open circuit case using the new algorithm

\section{Fully SENSORLESS SPEED CONTROL}

The position and speed control for a PM machine have been implemented in simulation in the Saber modeling environment. The estimated position signals $\mathrm{P} \alpha \beta$ from the equations selected, are used as the input to a mechanical observer [13] to obtain the speed $\omega^{\wedge}$ and a "cleaned" position $\theta^{\wedge}$. Note the simulation includes a minimum pulsewidth of 10us when $\mathrm{di} / \mathrm{dt}$ measurements are made - a realistic values seen from experimental results of [6]. This estimated speed $\omega^{\wedge}$ and position $\theta^{\wedge}$ are used to obtain a fully sensorless speed control as shown in Fig 6.

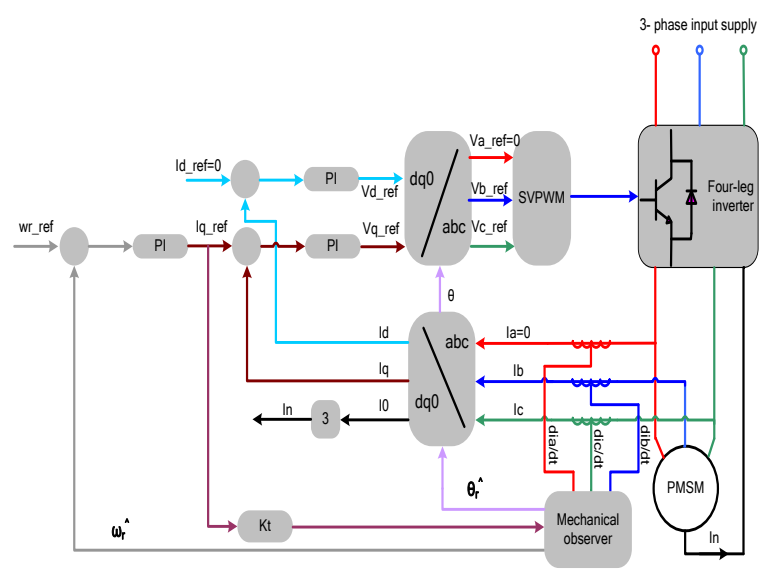

Fig10. the sensorless vector control structure for the four-phase inverter PMSM drive under a phase ' $b$ ' open-circuit fault.

Figure 11 shows the results of a fully sensorless speed control of a PMSM motor driven by a four-leg inverter at loaded conditions using the algorithm proposed in [6] for the healthy 
case and the method proposed above in the case of open circuit fault condition. The motor was working in sensorless healthy mode at speed $=0.5 \mathrm{~Hz}$ then at time $\mathrm{t}=7.5 \mathrm{~s}$ a speed step change from $0.5 \mathrm{~Hz}$ to $0 \mathrm{rpm}$ (till $\mathrm{t}=8.5 \mathrm{~s}$ ) is applied to the system. Fig 11 shows that the motor responded to the speed step with a good transient and steady state response. Moreover, as the motor is in healthy mode, $\mathrm{In}=0$ and the current are 3 balanced sinusoidal wave forms when speed_ref $=0.5 \mathrm{~Hz}$. At time $\mathrm{t}=8.5 \mathrm{~s}$, an open circuit fault in phase $\mathrm{b}$ was introduced to the system, this can be noticed form In \#0 and the current waveforms ( $\mathrm{Ib}=0$, Ia and Ic are multiplied by $\sqrt{3}$ and shifted by 60 degrees). Fig 11 shows that performance of the whole system under faulty condition is in the same level of the performance in healthy mode. Moreover the motor responded to a speed step from 0 to $0.5 \mathrm{~Hz}$ at $\mathrm{t}=10.5$ with acceptable transient and steady state performance.

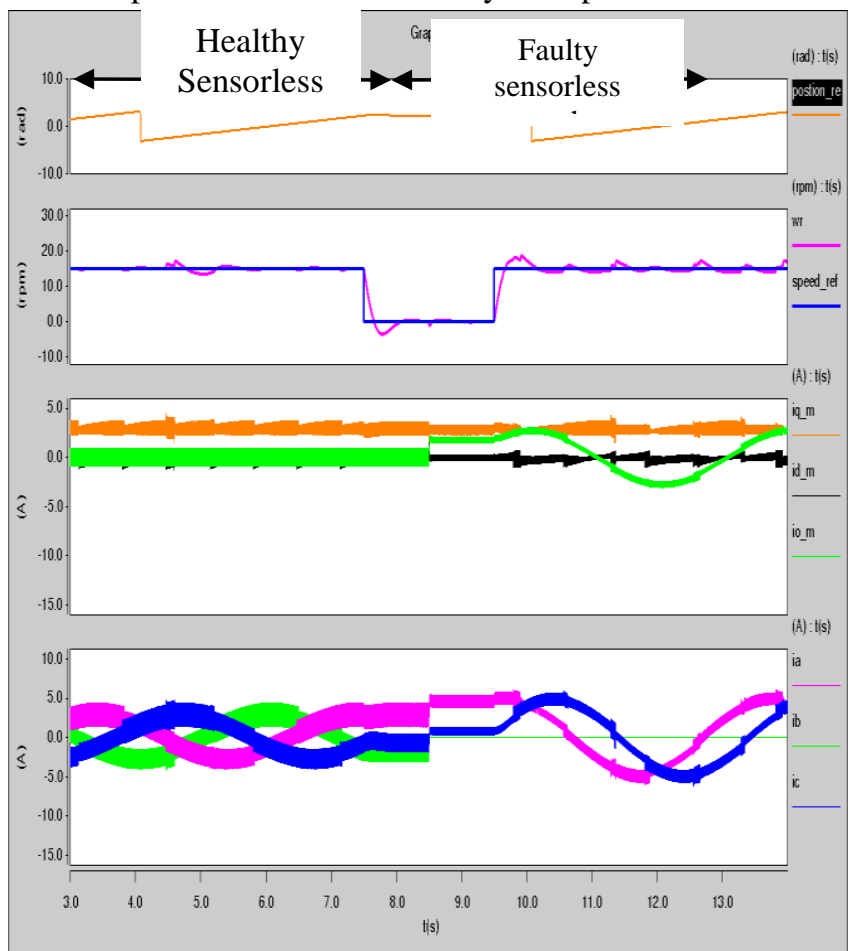

Fig 11 Fully Sensorless Speed Steps between $0.5 \mathrm{~Hz}, 0$ to 0.5

$\mathrm{Hz}$ half under healthy condition and under open phase $\mathrm{b}$ fault condition.

Fig 12 shows results similar to results shown in Fig 11 but with higher speed steps commanded from the system. The fig shows the effectiveness of the system to response to the high speed steps (from $10 \mathrm{~Hz}$ to 0 back to $10 \mathrm{~Hz}$ ) in the healthy case as well as the case of open circuit in phase b.

Fig 13 demonstrate the stability of the fully sensorless system when a load disturbance where applied at low speed $(1 \mathrm{~Hz})$ in both healthy mode and under open phase fault conditions. The results shows that the system maintain the speed in all the cases.

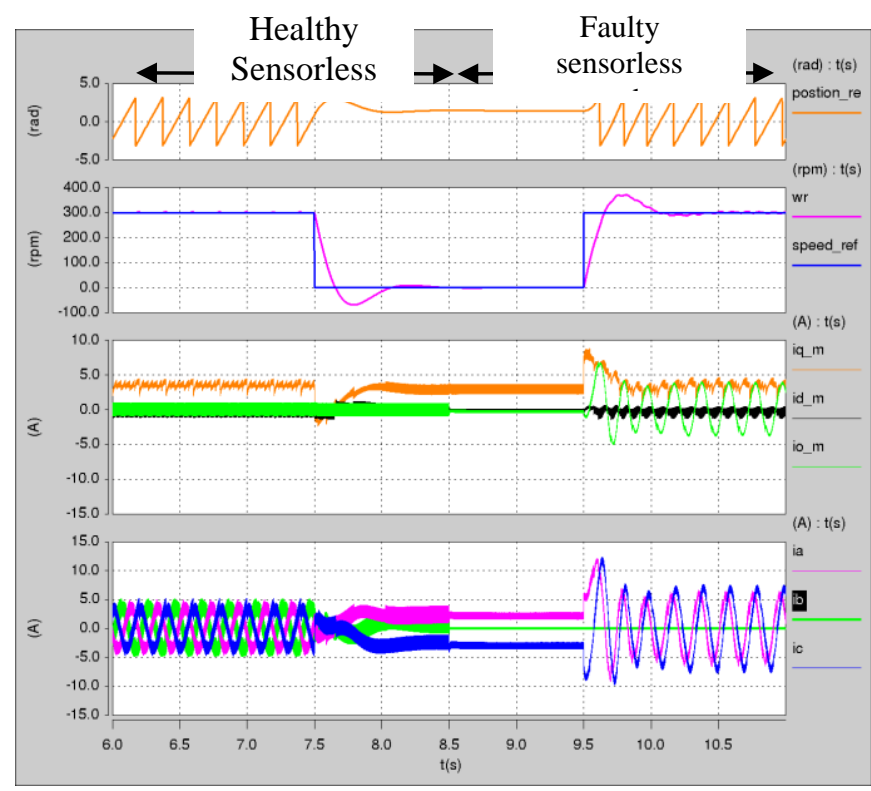

Fig 12 Fully Sensorless Speed Steps between $10 \mathrm{~Hz}, 0$ to 10 $\mathrm{Hz}$ half under healthy condition and under open phase a fault condition.

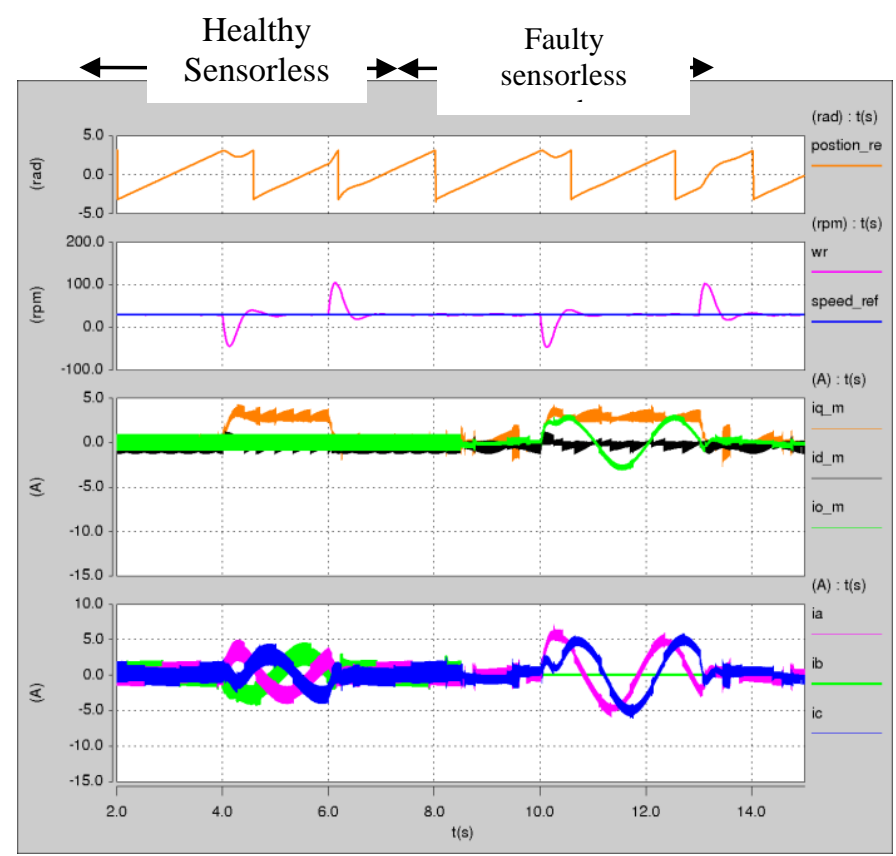

Fig 13 Fully Sensorless half load Steps under healthy condition and under open phase a fault condition.

\section{CONCLUSION}

This paper has outlined a new scheme for tracking the saliency of motor fed by a four-leg inverter in case of a single phase open circuit fault through measuring the dynamic current response of the motor line currents due the IGBT switching actions. The proposed method includes software modification to the method proposed in[6] to track the saliency of the motor under healthy condition to make it applicable in the cases of open circuit phase condition. The new strategy can be used to track the saturation saliency in PM and the rotor slotting saliency in induction motors. The results have shown the effectiveness of 
the new method in increasing the safety measures in critical systems needs a continued operation.

\section{REFERENCES}

[1] P.L. Jansen, R.D. Lorenz, ’Transducerless Position and Velocity Estimation in Induction and Salient AC Machines", IEEE Transactions on Industry Applications, vol.31, pages:240-247, Mar, 1995.

[2] J.-I. Ha, M. Ohto, J.-H. Jang, S.-K. Sul," Design and Selection of AC Machines for Saliency-Based Sensorless Control", Industrial Applications Conference of IEEE, IAS Annual Meeting, vol.2, pages:1155-1162, 2000.

[3] M. Linke, R. Kennel, J. Holtz, "Sensorless Speed and Position Control of Synchronous Machines using Alternating Carrier Injection”, IEEE International Electric Machines and Drives Conference IEMDC03, vol.2, pages:1211-1217, 2003.

[4] M. Schroedl. "Sensorless Control of AC Machines at Low Speed and Standstill Based on the INFORM Method". IEEE IAS Annual Meeting, volume 4, pp. 270-277, (1996).

[5] J. Holtz, J. Juliet."Sensorless Acquisition of the Rotor Position Angle of Induction Motors With Arbitrary Stator Windings". IAS Annual Meeting, volume 2, pp.1675-1682, (2004).

[6] G. Qiang, G.M. Asher, M. Sumner, P. Makys. "Position Estimation of AC Machines at all Frequencies Using Only Space Vector PWM based Excitation”, 3rd IET International Conference, pp. 61-70, (2006).

[7] M. S. Mendes and A. J. Cardoso. "Fault-tolerant operating strategies applied to three-phase induction motor drives", IEEE Trans. Ind Electron., vol. 53, pp. 1807-1817, (2006).

[8] N. Bianchi, S. Bolognani, M. Zigliotto, M. Zordan."Innovative remedial strategies for inverter faults in IPM synchronous motor drives", IEEE Trans. Eng Conv., vol. 18, pp. 306-314, (2003).

[9] F. Meinguet and J. Gyselinck. "Control strategies and reconfiguration of four-leg inverter PMSM drives in case of single-phase open circuit fault", IEEE IEPDC, pp. 299-304, (2009).

[10] S. Kwak, T. Kim and o. Vodyakbo. "Four-leg based matrix converter with fault resilient structure and controls for electric vehicle and propulsion systems", IEEE VPPC, pp. 519-523, (2007).

[11] B. A. Welchko, T. A. Lipo, T. M. Jahns and S. E.Schulz. "Fault tolerant three-phase ac motor drive

topologies: a comparison of features, cost, and limitation", IEEE Trans. Pow. Electron., vol. 19, pp. 1108-1116, (2004).

[12] S. Khwan-on, L. De Lillo, P. W. Wheeler, and L. Empringham, "Fault tolerant four-leg matrix converter motor drive topologies for aerospace applications," in Proc. IEEE ISIE, 2010, pp. 2166-2171.

[13] R.D. Lorenz , K.W. Van Patten. "High-Resolution Velocity Estimation for All-Digital, ac Servo Drives", IEEE transactions on industry applications, volume 27, pp.701 - 705, (1991).

[14] Tian-Hua Liu,Jen-Ren Fu, T.A.Lipo. “A strategy for improving Reliabilty of Field-Oriented Controlled Induction Motor Drives". IEEE transactions on industry applications, volume 29 , pp.910 - 918, (1993).

[15] Gaeta, A. ; Scelba, G. ; Consoli, A. "Modeling and Control of Three-Phase PMSMs Under Open-Phase Fault". IEEE transactions on industry applications, Volume: 49 , Issue: 1, 2013 , Page(s): 74 - 83
[16] MirafZal, B. "Survey of FAult-Tolerance TeChNiques For THREEPhase VOlTAGE SOURCE INVERTERs”. IEEE TRANSACTIONS ON INDUSTRIAL Electronics, Volume: 61 ,, 2014 , PAGE(S): 5192 - 5202

[17] Viola, J. ; Univ. Simon Bolivar, Caracas, Venezuela ; Quizhpi, F. ; Restrepo, J. ; Pesantez, J.P. "Analysis of a four-phase induction machine with direct torque control" . 15th European Conference on Power Electronics and Applications (EPE), 2013, Page(s): 1 - 9

[18] Nguyen-Duy, K. ; Taipei, Nat. Taiwan Univ. of Sci. \& Technol., Taipei, Taiwan ; Tian-Hua Liu ; Der-Fa Chen ; Hung, J.Y. “ Improvement of Matrix Converter Drive Reliability by Online Fault Detection and a Fault-Tolerant Switching Strategy". Transactions on Industrial Electronics , Volume:59, Issue: 1, 2012 , Page(s): $244-256$

[19] Santos Mendes, A.M. ; Abadi, M.B. ; Cruz, S.M.A. “ Fault diagnostic algorithm for three-level neutral point clamped AC motor drives, based on the average current Park's vector y”. Power Electronics, IET, Volume: 7 , Issue: 5 , 2014, Page(s): 1127 - 1137 